\title{
FORMULASI DAN UJI AKTIVITAS ANTIJAMUR SEDIAAN KRIM EKSTRAK METANOL KETEPENG CINA (Cassia alata L.) TERHADAP JAMUR Candida albicans
}

\section{FORMULATION AND TEST EFFECTIVENESS OF ANTIFUNGAL CREAM OF CANDLE TREE METHANOL EXTRACT (Cassia alata L.) ON Candida albicans}

\author{
Ricky C. Rumayar ${ }^{1)}$, Paulina V.Y Yamlean ${ }^{1)}$, Jainer Pasca Siampa ${ }^{1)}$ \\ ${ }^{1)}$ Program Studi Farmasi FMIPA UNSRAT Manado, 95115 \\ *Rickychandrarumayar@gmail.com
}

\begin{abstract}
Candle tree is widely used traditionally as an antiparasitic and antifungal. Candle tree leaves have important ingredients such as alkaloids, saponins, tannins, steroids, anthraquinones, flavonoids. This study aims to formulate, evaluate, and test the antifungal effectiveness of cream preparations with $M / A$ cream types of methanol extract of Candle tree (cassia alata L.) leaves at a concentration of 3.5\%; $5.5 \%$ and $7.5 \%$. Antifungal effectiveness tests were performed using the diffusion method for creams with the largest antifungal activity. Then the results of testing the effectiveness of the largest antifungal cream was obtained at a concentration of $7.5 \%$ with a $9.5 \mathrm{~mm}$ diameter of inhibition zone. Physical evaluation of the preparation includes organoleptic test, homogeneity test, $\mathrm{pH}$ test, dispersion test, adhesion test, and cycling test. All tests are carried out before and after cyling test. The results of the cream preparation study met the physical evaluation requirements before the cycling test and after the cyling test. Antifungal cream showed organoleptic, homogeneity, $\mathrm{pH} 8$, spreadability test $6.67 \mathrm{~cm}$ and adhesion test 27.41 seconds after storage did not change. In conclusions from the study of $3.5 \%$ concentration cream; $5.5 \%$ and $7.5 \%$ methanol extract of Candle tree leaves can be formulated as a cream preparation because it is physically stable and has strong antifungal activity.
\end{abstract}

Keywords: Candle tree (cassia alata L.), Cream, Candida albicans, Antifungal

\begin{abstract}
ABSTRAK
Ketepeng cina banyak dimanfaatkan secara tradisional, antara lain adalah sebagai antiparasit dan antijamur Daun ketepeng cina memiliki kandungan penting seperti alkaloid, saponin, tannin, steroid, antrakuinon, flavonoid. Penelitian ini bertujuan untuk memformulasi, mengevaluasi, serta menguji efektivitas antijamur sediaan krim dengan tipe krim M/A daun ekstrak metanol ketepeng cina (cassia alata L.) pada konsentrasi 3,5\%; 5,5\% dan 7,5\%. Uji efektivitas antijamur dilakukan dengan metode difusi untuk krim dengan aktivitas antijamur terbesar. Kemudian dilakukan hasil pengujian efektivitas krim antijamur terbesar diperoleh pada konsentrasi $7,5 \%$ dengan diameter zona hambat $9,5 \mathrm{~mm}$. evaluasi fisik sediaan meliputi uji organoleptic, uji homogenitas, uji $\mathrm{pH}$, uji daya sebar, uji daya lekat, dan uji cycling test semua pengujian dilakukan sebelum dan sesudah cyling test. Hasil penelitian sediaan krim memenuhi persyaratan evaluasi fisik sebelum uji cycling test dan setelah cyling test. Krim antijamur memperlihatkan organoleptic, homogenitas, $\mathrm{pH} 8$, uji daya sebar $6,67 \mathrm{~cm}$ dan uji daya lekat 27,41 detik setelah penyimpanan tidak terjadi perubahan. Kesimpulan dari penelitan pada krim konsentrasi 3,5\%; 5,5\% dan 7,5\% ekstrak metanol daun ketepeng cina dapat diformulasi sebagai sediaan krim karena stabil secara fisik dan memiliki aktivitas antijamur yang kuat.
\end{abstract}

Kata kunci : Ketepeng cina (cassia alata L.), Krim, Candida albicans, Antijamur 


\section{PENDAHULUAN}

Candida albicans merupakan flora normal pada membrane mukosa rongga mulut, saluran pernafasan, saluran pencernaan dan organ genitalia perempuan. Candida albicans dikenal sebagai mikroorganisme oportunistik pada tubuh manusia, pada keadaan tertentu jamur ini mampu menyebabkan infeksi dan kerusakan jaringan. Jamur ini adalah bagian dari flora normal (komensal) selaput lendir di saluran pernafasan, saluran cerna dan saluran vagina (Tjay, 2007).

Indonesia sudah terkenal merupakan negara yang kaya bahan alam. Salah satu bahan alam yang memiliki potensi untuk diteliti adalah ketepeng cina (Cassia alata L.). Selama ini ketepeng cina banyak dimanfaatkan secara tradisional, antara lain adalah sebagai antiparasit, laksan, kurap, kudis, panu, eksem, malaria, sembelit, radang kulit bertukak, sifilis, herpes, influenza dan bronchitis. Daun ketepeng cina memiliki kandungan penting seperti alkaloid, saponin, tannin, steroid, antrakuinon, flavonoid dan karbohidrat. Flavonoid pada tanaman herbal memiliki efek antiinflamasi, antialergi, antibakteri terhadap Aspergillus fumigatus and Microsporum canis (Somchit et al., 2002; Phongpaicit et al., 2004), antioksidan, dan efektif untuk beberapa golongan jamur (Rahman, 2010).

Menurut penelitian Oktoviany, (2017) menyatakan ekstrak metanol Ketepeng cina memiliki aktivitas paling baik karena pada konsentrasi rendah telah memberikan zona hambat yang besar. Pada konsentrasi 5\% terjadi aktivitas antijamur yang paling besar yaitu 20,30 $\mathrm{mm}$ merupakan konsentrasi paling efektif dari ekstrak metanol.

Bentuk sediaan Krim lebih disukai oleh masyarakat karena mudah dibersihkan dan mudah menyebar (Ansel, 2005). Krim dipilih karena merupakan salah satu bentuk sediaan topikal umumnya yang digunakan untuk terapi yang bersifat lokal (Anief, 1996).

\section{METODOLOGI PENELITIAN Waktu dan Tempat}

Penelitian ini dilaksanakan pada bulan Agustus 2019 - Juni 2020 di Laboratorium Penelitian Farmasi Lanjut dan Laboratorium Biologi Dasar, Fakultas Matematika dan Ilmu Pengetahuan Alam, Universitas Sam Ratulangi, Manado.

\section{Bentuk Penelitian}

Bentuk Penelitian ini menggunakan metode eksperimental untuk formulasi sediaan krim dari ekstrak daun Ketepeng cina dan pengujian efektivitas antibakteri dari ekstrak daun Ketepeng cina terhadap bakteri Candida albicans.

\begin{abstract}
Alat dan Bahan
Alat

Alat yang digunakan dalam penelitian ini ialah alat-alat gelas (Iwaki ST Pyrex ${ }^{\circledR}$ ), timbangan digital $\left(\right.$ AE Adam $\left.{ }^{\circledR}\right)$, hotplate magnetic stirrer (Nesco $\left.{ }^{\circledR} \mathrm{Lab}\right)$, mikropipet, $\mathrm{pH}$ meter, oven, autoklaf $\left(A L P^{\circledR}\right)$, inkubator $\left(\right.$ Ecocell $\left.^{\circledR}\right), \quad$ fungi coloni counter $\left(\right.$ Health $\left.^{\circledR}\right)$, blender $\left(\right.$ Miyako $\left.{ }^{\circledR}\right)$, penggaris berskala, jangka sorong, wadah krim, lemari pendingin, ayakan 60 mesh.
\end{abstract}

\section{Bahan}

Bahan yang digunakan dalam penelitian ini ialah ekstrak daun Ketepeng cina, medium PDA, asam stearat, gliserin, metil paraben, propil paraben, paraffin cair, adeps lanae, aquades, krim ketoconazole, jamur Candida albicans, alumunium foil.

\section{Prosedur Penelitian}

Pengambilan Sampel

Sampel yang digunakan di ambil dari desa

Tateli, Kabupaten Minahasa, Sulawesi Utara

\section{Identifikasi Sampel}

Identifikasi tanaman dilakukan di Laboratorium Taksonomi Tumbuhan, Jurusan 
Biologi, Fakultas Matematika dan Ilmu Pengetahuan Alam, Universitas Sam Ratulangi Manado.

\section{Ekstraksi}

Pada tahap ini sampel diekstraksi dengan metode maserasi yaitu dengan cara simplisia Daun Ketepeng Cina direndam menggunakan metanol 96\% pada maserator sampel daun Ketepeng Cina (Casia alata L.) terlebih dahulu ditimbang sebanyak 400 gram, kemudian sampel direndam menggunakan pelarut metanol $96 \%$ yang di tempatkan pada maserator, sampai serbuk terendam semua (volume metanol $\pm 2 \mathrm{~L}$ ), diaduk dengan menggunakan magnetik stirer selama \pm 2 jam. Setelah itu sampel didiamkan selama 3 x 24 jam dengan sesekali diaduk. Selanjutnya sampel di saring menggunakan kertas saring, Hingga didapatkan ekstrak cair.

Residu yang tertinggal ditambah lagi dengan metanol $(1,5 \mathrm{~L})$ dan diberikan perlakuan yang sama kemudian diulangi lagi. Selanjutnya semua Ekstrak cair yang didapat dikumpulkan menjadi satu untuk dievaporasi sampai agak kental. Setelah agak kental, diuapkan di atas waterbath suhu $50^{\circ} \mathrm{C}$ untuk mendapatkan ekstrak yang lebih pekat.

\section{Formulasi Sediaan Krim}

Tabel 1. Formula Sediaan krim ekstrak metanol daun ketepeng cina (Cassia alata L.)

\begin{tabular}{ccccc}
\hline \multirow{2}{*}{ Bahan } & \multirow{2}{*}{ Fungsi } & \multicolumn{3}{c}{ Konsentrasi \% b/v } \\
\cline { 3 - 5 } & F1 3,5\% & F2 5,5\% & F3 7,5\% \\
\hline $\begin{array}{c}\text { Ekstrak Metanol } \\
\text { Daun Ketepeng } \\
\text { Cina }\end{array}$ & Zat Aktif & $1,75 \mathrm{~g}$ & $2,75 \mathrm{~g}$ & $3,75 \mathrm{~g}$ \\
\hline Asam Stearat & Basis Krim & $7,25 \mathrm{~g}$ & $7,25 \mathrm{~g}$ & $7,25 \mathrm{~g}$ \\
\hline TEA & Pengemulsi & $0,75 \mathrm{~g}$ & $0,75 \mathrm{~g}$ & $0,75 \mathrm{~g}$ \\
\hline Adeps Lanae & $\begin{array}{c}\text { Zat } \\
\text { Tambahan }\end{array}$ & $1,5 \mathrm{~g}$ & $1,5 \mathrm{~g}$ & $1,5 \mathrm{~g}$ \\
\hline Parafin Cair & $\begin{array}{c}\text { Pelembab dan } \\
\text { Pelicin }\end{array}$ & $12,5 \mathrm{~g}$ & $12,5 \mathrm{~g}$ & $12,5 \mathrm{~g}$ \\
\hline Nipagin & Pengawet & $0,05 \mathrm{~g}$ & $0,05 \mathrm{~g}$ & $0,05 \mathrm{~g}$ \\
\hline Nipasol & Pengawet & $0,025 \mathrm{~g}$ & $0,025 \mathrm{~g}$ & $0,025 \mathrm{~g}$ \\
\hline Aquades (ad) & Pelarut & 50 & 50 & 50 \\
\hline
\end{tabular}

\section{Pembuatan Krim}

Basis Krim tipe M/A yang dibuat terdiri dari dua fase yaitu fase minyak (parafin cair, adeps lanae, asam stearat, nipasol) dan fase air (TEA, nipangin). Fase - fase tersebut dipanaskan pada suhu $70^{\circ} \mathrm{C}$ di tangas air. Fase minyak dipindahkan kedalam lumpang dan yang telah berisi fase air, kemudian diaduk sampai homogen hingga terbentuk massa Krim.

Pembutan Krim ekstrak daun Ketepeng cina dengan cara mencampurkan basis Krim dengan ekstrak daun Ketepeng cina sesuai dengan konsentrasi. Formulasi Krim ekstrak Daun Ketepeng cina dengan konsentrasi 3,5\%; 5,5\%; $7,5 \%$.

\section{Uji Mutu Sediaan Krim}

\section{Uji Organoleptis}

Pemeriksaan organoleptis meliputi bentuk, warna dan bau yang diamati secara visual Spesifikasi Krim yang harus dipenuhi adalah memiliki konsistensi lembut, warna sediaan homogen, dan harum. (Erawati et al., 2016).

\section{Uji Homogenitas}

Uji homogenitas dilakukan dengan meletakkan Krim secukupnya diantara dua kaca objek, kemudian diamati adanya butiran kasar atau tidak (Setiawati et al., 2014). 


\section{Uji Daya Sebar}

Krim ditimbang $1 \mathrm{~g}$, lalu diletakan di atas plat kaca, biarkan 1 menit, ukur diamter sebar Krim, kemudian ditambah dengan beban $50 \mathrm{~g}$, beban didiamkan selama 1 menit, lalu diukur diameter sebarnya. Hal tersebut dilakukan sampai didapat diameter sebar yang konstan (Rahmawati et al., 2010).

\section{Uji Daya Lekat}

Pengujian daya lekat sediaan dilakukan dengan cara Krim diletakkan pada satu sisi kaca objek dengan sisi bawahnya telah dipasangkan tali untuk mengikat beban. Kemudian ditempelkan pada kaca objek yang lain. Beban yang digunakan adalah $80 \mathrm{~g}$. Kemudian diamati waktu yang dibutuhkan beban tersebut untuk memisahkan kedua kaca. Waktu dicatat sampai kedua plat saling lepas. Replikasi dilakukan sebanyak 3 kali (Rahmawati et al., 2010).

\section{Pengukuran pH}

Uji $\mathrm{pH}$ bertujuan mengetahui keamanan sediaan krim saat digunakan sehingga tidak mengiritasi kulit. Ditimbang sebanyak 1 gram ekstrak krim dan diencerkan dengan $10 \mathrm{ml}$ aquades. Kemudian gunakan pH-meter yang bagian sensornya dan dibaca $\mathrm{pH}$ pada bagian monitor. $\mathrm{pH}$ sediaan yang memenuhi kriteria $\mathrm{pH}$ kulit yaitu dalam interval 4,5 - 6,5 (Tranggono dan Latifa, 2007).

\section{Uji Stabilitas Krim (Cycling test)}

Pengujian stabilitas pada penelitian ini menggunakan dengan cycling test. Sampel krim disimpan pada suhu $4^{\circ} \mathrm{C}$ selama 24 jam dan suhu $40^{\circ} \mathrm{C}$ selama 24 jam dilakukan sebanyak 6 siklus dan diamati terjadinya perubahan fisik dari krim pengamatan organoleptik, homogenitas, $\mathrm{pH}$, daya lekat, daya sebar, pengukuran viskositas (Dewi, 2010).

\section{Uji Efektivitas Antibakteri}

Uji Efektivitas antijamur terhadap krim ekstrak daun ketepeng cina menggunakan jamur Candida albicans dengan cara difusi. Digunakan 3 sumuran untuk setiap konsentrasi krim ekstrak ketepeng cina 3,5\%; 5,5\%; 7,5\% dan 2 sumuran lain untuk kontrol positif (krim ketoconazole) dan kontrol negatif (basis krim). Masing-masing diambil 0,1g dan dimasukkan pada setiap sumuran kemudian diinkubasi pada suhu $37^{\circ} \mathrm{C}$ selama $3 \times 24$ jam.

\section{HASIL DAN PEMBAHASAN}

Hasil Pengujian Antijamur krim ekstrak metanol daun ketepeng cina Tabel 2 .

Tabel 2. Hasil Pengujian Antijamur

\begin{tabular}{cc}
\hline & $\begin{array}{l}\text { Rata-Rata diameter daerah hambatan } \\
(\mathrm{mm})\end{array}$ \\
\hline $\mathrm{K}(-)$ & 0 \\
$\mathrm{~K}(+)$ & 11 \\
$\mathrm{FI}$ & 5,16 \\
$\mathrm{FII}$ & 6,66 \\
FIII & 9,5 \\
\hline Keterangan : K(-) : Basis krim tanpa ekstrak; K(+) : Krim \\
Ketoconazole; FI : Formulasi sediaan krim ekstrak metanol \\
daun Ketepeng cina konsentrasi 3,5\%; FII : Formulasi \\
sediaan krim ekstrak metanol daun Ketepeng Cina \\
konsentrasi 5,5\%; FIII : Formulasi sediaan krim ekstrak \\
metanol daun Ketepeng cina konsentrasi 7,5\%
\end{tabular}

Pengujian antijamur esktrak metanol daun ketepeng cina terhadap Candida albicans dilakukan tiga kali pengulangan pada konsentrasi $3.5 \% ; 5,5 \% ; 7,5 \%$. Pengujian ini perlu untuk dilakukan untuk melihat pada konsentrasi yang paling optimal untuk menghambat pertumbuhan jamur Candida albicans, ditandai dengan tidak adanya pertumbuhan jamur pada media PDA. sehingga ketika sudah mendapatkan konsentrasi optimal itulah yang akan digunakan untuk uji fisik dan sterilitas. Pengujian antijamur dengan menggunakan jamur Candida albicans yang dilihat dari daya hambat ini dimaksudkan untuk mengetahui besarnya pelepasan zat aktif dengan mengukur diameter zona hambat pertumbuhan jamur. Daya hambat menurut Puthera et al., (2007) terbagi atas : sangat kuat (zona hambat > $2 \mathrm{~cm}$ ), kuat (zona hambat 1,6-2 cm), sedang (zona hambat 1-1,5 cm) dan lemah (zona hambat <1 $\mathrm{cm})$. Pengujian aktivitas antijamur ditentukan berdasarkan diameter zona hambat disekitar pencadangan/sumuran media Potato Dextrose Agar (PDA). 
Hasil pengujian yang didapat dengan konsentrasi 3,5\%; 5,5\% dan 7,5\% menunjukan aktivitas antijamur dengan adanya zona hambat disekitar sumuran. Diameter zona hambat disekitar sumuran diukur menggunakan jangka sorong dengan cara mengukur secara horizontal dan vertikal kemudian hasil yang didapatkan dikurangi diameter sumuran $7 \mathrm{~mm}$. Krim ekstrak metanol daun Ketepeng cina konsentrasi 3,5\% memberikan daya hambat $5,16 \mathrm{~mm} ; 5,5 \%$ memberikan daya hambat $6,66 \mathrm{~mm} ; 7,5 \%$ memberikan daya hambat $9,5 \mathrm{~mm}$ dari hasil ke 3 konsentrasi tersebut dapat dikategorikan memiliki daya hambat yang sedang kontrol positif memberikn daya hambat $11 \mathrm{~mm}$ dan kontrol negatif tidak memberikan daya hambat karena menghasilkan zona hambat $0 \mathrm{~mm}$. dari hasil tersebut dapat dilihat bahwa krim ekstrak metanol daun Ketepeng cina dengan konsentrasi 3,5\%; 5,5\% dan 7,5\% bisa menghambat aktivitas jamur Candida albicans dengan menjadikan konsentrasi optimal yaitu 7,5\% dikarenakan pada konsentrasi $7,5 \%$ memiliki daya hambat yang paling besar. Zona hambat yang terbentuk karena adanya senyawa antijamur pada daun Ketepeng cina. senyawa flavonoid, saponin, dan tannin. Dari hasil yang didapat menunjukkan semakin tinggi konsentrasi sediaan krim maka semakin besar daya hambat yang dihasilkan.

\section{Evaluasi Sediaan Krim Ekstrak Metanol Daun Ketepeng Cina \\ Uji Organoleptik}

Pada pengujian organoleptik yang meliputi warna, aroma dan bentuk menunjukkan bahwa formulasi krim yang dihasilkan berwarna hijau, memiliki bau khas ekstrak metanol daun ketepeng cina dengan bentuk semi padat. Semakin tinggi penambahan konsentrasi ekstrak daun ketepeng cina, maka semakin kuat bau khas ekstrak metanol daun ketepeng cina dan warna hijau yang dihasilkan krim.

Setelah dilakukan penyimpanan di dalam suhu $4^{\circ} \mathrm{C}$ dan $40^{\circ} \mathrm{C}$ tidak terjadi perubahan warna, aroma, dan bentuk pada sediaan krim, ini dapat diartikan bahwa krim ekstrak metanol daun ketepeng cina memiliki stabilitas yang baik dalam penyimpanan karena tetap sama pada waktu sebelum penyimpanan dan sesudah penyimpanan.

\section{Uji Homogenitas}

Pada pengujian homogenitas ini bertujuan untuk melihat dan mengetahui tercampurnya bahan-bahan sediaan krim sehingga tidak terlihat adanya butiran-butiran kasar. Hasil dari pengujian ini menunjukan bahwa krim memiliki susunan yang homogen serta tidak ada butiran kasar.

Hal ini sesuai dengan persyaratan homogenitas krim yaitu krim harus memiliki susunan yang homogen serta tidak adanya butiran kasar pada krim. Krim tersebut dikatakan homogen jika terdapat persamaan warna yang merata dan tidak ditemukan partikel dalam krim (Ida dan Noer, 2012).

\section{Uji pH}

Tabel 3. Hasil pengujian $\mathrm{pH}$

\begin{tabular}{c|c|c}
\hline Krim & $\begin{array}{c}\text { Sebelum } \\
\text { penyimpanan } \mathrm{pH}\end{array}$ & $\begin{array}{c}\text { Setelah } \\
\text { penyimpanan } \mathrm{pH}\end{array}$ \\
\hline Basis & 8,4 & 8,1 \\
$\mathrm{~K} 3,5 \%$ & 8,1 & 8,0 \\
$\mathrm{~K} 5,5 \%$ & 8,3 & 8,1 \\
$\mathrm{~K} 7,5 \%$ & 8,4 & 8,1 \\
\hline
\end{tabular}

Keterangan : Siklus 0 : Siklus 0 sebelum cycling test sediaan krim konsentrasi 7,5\% ; Siklus 1 : Siklus 1 setelah cycling test sediaan krim konsentrasi 7,5\%; Siklus 2 : Siklus 2 setelah cycling test sediaan krim konsentrasi 7,5\%; Siklus 3: Siklus 3 setelah cycling test sediaan krim konsentrasi 7,5\%; Siklus 4 : Siklus 4 setelah cycling test sediaan krim konsentrasi 7,5\%; Siklus 5: Siklus 5 setelah cycling test sediaan krim konsentrasi 7,5\%; Siklus 6 : Siklus 6 setelah cycling test sediaan krim konsentrasi 7,5\%.

Penentuan $\mathrm{pH}$ sediaan dilakukan dengan menggunakan alat digital $\mathrm{pH}$ meter. Dan di dapat hasil $\mathrm{pH}$ dengan kisaran 8,0-8,4 yang berarti krim memiliki sedikit sifat basa dikarenakan penggunaan TEA yang bersifat basa (Kurniasih 2016). Nilai $\mathrm{pH}$ tersebut berada dalam kisaran nilai $\mathrm{pH}$ yang terdapat pada SNI 16-4399-1996 sebagai syarat mutu pelembab kulit $(4,5-8,0 \mathrm{pH})$ dan kisaran pH normal kulit yaitu 4,5-6,5 (Rizky et al., 2013). 


\section{Uji Daya Lekat}

Tabel 4. Hasil Pengujian Daya Lekat Krim Ekstrak Metanol Daun Ketepeng cina.

\begin{tabular}{l|l}
\hline & Rata-rata \\
\hline Siklus ke- 0 & 33,7 detik \\
Siklus ke- 1 & 31,3 detik \\
Siklus ke- 2 & 30 detik \\
Siklus ke- 3 & 28,3 detik \\
Siklus ke- 4 & 27,3 detik \\
Siklus ke- 5 & 25,3 detik \\
Siklus ke- 6 & 22,3 detik \\
\hline
\end{tabular}

keterangan : Siklus 0 : Siklus 0 sebelum cycling test sediaan krim konsentrasi 7,5\%; Siklus 1 : Siklus 1 setelah cycling test sediaan krim konsentrasi 7,5\%; Siklus 2 : Siklus 2 setelah cycling test sediaan krim konsentrasi 7,5\%; Siklus 3: Siklus 3 setelah cycling test sediaan krim konsentrasi 7,5\%; Siklus 4 : Siklus 4 setelah cycling test sediaan krim konsentrasi 7,5\%; Siklus 5: Siklus 5 setelah cycling test sediaan krim konsentrasi 7.5\%; Siklus 6 : Siklus 6 setelah cycling test sediaan krim konsentrasi $7,5 \%$.

Pada pengujian daya lekat dilakukan untuk mengukur kemampuan krim untuk melekat pada saat diaplikasikan pada kulit, hasil dari pengujian daya lekat dari krim sebelum dan sesudah penyimpanan dalam suhu $4^{\circ} \mathrm{C}$ dan $40^{\circ} \mathrm{C}$ didapat rata-rata 27,41 detik, sesuai persyaratan daya lekat krim yang baik yaitu lebih dari 4 detik menunjukkan bahwa krim ekstrak metanol daun ketepeng cina memiliki daya lekat yang baik, karena semakin lama krim melekat pada kulit maka semakin banyak zat aktif yang diabsorbsi dan krim akan memberikan efek terapi yang lebih optimal (Wasiaatmadja, 1997).

\section{Uji Daya Sebar}

Tabel 5. Hasil Uji Daya Sebar

\begin{tabular}{l|l}
\hline & Rata-rata \\
\hline Siklus ke- 0 & 6,23 \\
Siklus ke- 1 & 6,27 \\
Siklus ke- 2 & 6,24 \\
Siklus ke- 3 & 6,36 \\
Siklus ke- 4 & 6,48 \\
Siklus ke- 5 & 7,17 \\
Siklus ke- 6 & 7,52 \\
\hline
\end{tabular}

keterangan : Siklus 0 : Siklus 0 sebelum cycling test sediaan krim konsentrasi 7,5\%; Siklus 1 : Siklus 1 setelah cycling test sediaan krim konsentrasi 7,5\%; Siklus 2 : Siklus 2 setelah cycling test sediaan krim konsentrasi 7,5\%; Siklus 3: Siklus 3 setelah cycling test sediaan krim konsentrasi 7,5\%; Siklus 4 : Siklus 4 setelah cycling test sediaan krim konsentrasi 7,5\%; Siklus 5: Siklus 5 setelah cycling test sediaan krim konsentrasi 7,5\%; Siklus 6 : Siklus 6 setelah cycling test sediaan krim konsentrasi $7,5 \%$.

Pada pengujian daya sebar dilakukan untuk melihat kemampuan menyebar sediaan krim pada permukaan kulit pada saat pemakaian, hasil dari pengujian daya sebar dari krim sebelum dan sesudah penyimpanan dalam suhu $4^{\circ} \mathrm{C}$ dan $40^{\circ} \mathrm{C}$ didapat rata-rata $6,67 \mathrm{~cm}$, sesuai dengan persyaratan yang baik akan menghasilkan daya sebar sebesar 5-7 cm (Wasiaatmadja, 1997) menunjukkan bahwa krim ekstrak metanol daun ketepeng cina memiliki daya sebar yang baik. Daya sebar yang baik menyebabkan kontak antara obat dengan kulit menjadi luas, sehingga absorpsi obat ke kulit berlangsung cepat.

\section{KESIMPULAN}

Berdasarkan hasil penelitian maka dapat disimpulkan bahwa :

1. Ekstrak metanol daun ketepeng cina dapat diformulasikan menjadi sediaan krim dengan konsentrasi $3.5 \%$; $5,5 \%$ dan $7,5 \%$ dan telah memenuhi syarat parameter uji yaitu pengujian organoleptik, homogenitas, $\mathrm{pH}$, daya sebar, daya lekat, dan stabilitas.

2. Sediaan krim ekstrak metanol dapat memberikan efek antijamur terhadap jamur Candida Albicans dengan diameter rataratanya pada konsentrasi $3,5 \%(2,61 \mathrm{~mm})$; $5,5 \%(6,66 \mathrm{~mm})$ dan $7,5 \%(9,5 \mathrm{~mm})$.

3. Berdasarkan uji antijamur dan didapat daya hambat yang paling besar terdapat pada konsentrasi 7,5\%, maka konsentrasi optimum formula sediaan krim dari ekstrak metanol daun ketepeng cina (Cassia alata L.) adalah konsentrasi $7,5 \%$.

\section{SARAN}

Disarankan kepada penelitian selanjutnya untuk perlu dilakukan evaluasi fisik yang belum dilakukan dalam penelitian ini yaitu uji viskositas.

\section{DAFTAR PUSTAKA}

Anief, M, 1996, Penggolongan Obat Berdasarkan Khasiat dan Penggunaan, 9, Penerbit Universitas Gadjah Mada, Yogyakarta

Ansel, H. C., 2005, Pengantar Bentuk Sediaan Farmasi, diterjemahkan oleh Ibrahim, F., Edisi IV, UI Press, Jakarta. 
Dewi R.K. 2010. Optimasi Formulasi Mikroemulsi Sediaan Hormon Testosteron Undekanoa. Jakarta : Universitas Negeri Islam Negeri Syarif Hidayatullah.

Erawati, E., Pratiwi, D., Zaky, M., 2016. Pengembangan Formulasi dan Evaluasi Fisik Sediaan Krim Ekstrak Etanol 70\% Daun Labu Siam (Sechium edule (Jacq.)Swatz). Farmagazine 3(1), 1120.

Ida, N., Noer, S.F. 2012. Uji Stabilitas Fisik Gel Ekstrak Lidah Buaya (Aloe Vera L.). Majalah Farmasi dan Farmakologi. 16(2): 79-84.

Kurniasih N., 2016. Formulasi Sediaan Krim Tipe M/A Ekstrak Biji Kedelai (Glycine max L.) : Uji Stabilitas Fisik dan Efek pada Kulit. Universitas Muhammadiyah Surakarta.

Oktoviany Triana. Fajar Prasetya. Hadi Kuncoro. Laode Rijai, 2017. aktivitas antijamur ekstrak daun ketepeng cina (Cassia alata L.). Laboratorium Penelitian dan Pengembangan farmaka tropis, Fakultas Farmasi, Universitas Mulawarman, Kalimantan Timur. Samarinda. Jurnal Sains dan Kesehatan. Vol 1 (6).

Puthera, A., G.N Agung dan A.S Duniaji, 2007. Mempelajari Pengaruh Konsentrasi Ekstrak Rimpang Lengkuas Terhadap Pertumbuhan Aspergillus Flavus pada Kacang Tanah. Vol 4 (2)

Phongpaicit S, Pujenjob N, Rukachaisirikul V, Ongsakul M. 2004, Antifungal activity from leaf extracts of Cassia alata L., Cassia fistula L. and Cassia tora L. Songklanakarin J. Sci. Technol., 26(5) : 741-748.

Rahman A. 2010, Laboratory Handbook for Fractination of Natural Extracts. London.
Rahmawati D., Sukmawati A., Indrayudha P. (2010) Formulasi Krim minyak atsiri rimpang temu giring (Curcuma heyneana Val \& Zijp): uji sifat fisik dan daya antijamur terhadap Candida albicans secara in vitro. Maj. Obat Trad. 15:56-63.

Rizky, A.W., Latifa., dan Winarni, P. 2013. Formulasi Krim Ekstrak Lidah Buaya (Aloe vera) Sebagai Alternatif Penyembuhan Luka Bakar. Indonesian Journal of Chemical Science.

Setiawati, E., Nursal, F. K,. Elfiyani, R. 2014. Pengaruh Peningkatan Konsentrasi Setil Alkohol Sebagai Pengental Terhadap Stabilitas Fisik Krim Tipe M/A Ekstrak Rimpang Jahe Gajah (Zingiber Officinale Roscoe).: Fakultas Farmasi Universitas Muhamadiyah. Jakarta.

Somchit MN, Reezal I, Nur IE, Mutalib AR. 2002, In vitro antimicrobial activity of ethanol and water extracts of Cassia alata, Journal of Ethnopharmacology 84:1- 4 (2003).

Tranggono, R.I., Latifah, F. 2007. Buku Pegangan Ilmu Pengetahuan Kosmetik. Jakarta: Gramedia Pustaka Utama. Halaman 3336.

Tjay, Tan Hoan dan Kirana Rahardja. 2007, ObatObat Penting Khasiat, Penggunaan dan Efek-Efek Sampingnya, IV, 262, 269-271, PT. Elex Media Komputindo, Jakarta.

Wasitaatmadja, S.M. 1997. Penuntun Ilmu Kosmetik Medik. Jakarta: Penerbit Universitas Indonesia. Hal. 3,58-59.62rotsheki63. 111-112. 